\title{
A novel acute anemia model for pharmacological research in mice by compelled acute exercise
}

\author{
Qing-shan LIU ${ }^{2, \#}$, Jin-hua WANG ${ }^{1, \#}$, Jian CUI $^{2}$, Zhi-hong YANG ${ }^{1,3}$, Guan-hua DU ${ }^{1, *}$ \\ ${ }^{1}$ Institute of Materia Medica, Chinese Academy of Medical Science \& Peking Union Medical College, Beijing 100050, China; ${ }^{2}$ National \\ Research Center for Chinese Minority Nationality Medicine, Minzu University of China, Beijing 100081, China; ${ }^{3}$ Institute of Medicinal \\ Plant Development, Chinese Academy of Medical Science \& Peking Union Medical College, Beijing 100050, China
}

\begin{abstract}
Aim: To generate a novel acute anemia model by compelled exercise.
Methods: Young adult male mice were compelled to perform an acute exercise by electric stimulation for 30 min. Blood was taken from their tails to be used for detection immediately after exercise.

Results: It was found that the red blood cell (RBC) count, hemoglobin concentration and hematocrit of exhausted mice were lower than that of sedentary mice without electric stimulation. The model is in line with the diagnostic criteria. As the mechanisms of the acute anemia model, it was found that the osmotic fragility of the RBC in model mice increased compared to that of normal mice, and that the deformation index, orientation index, small deformation index, deformability and orientation of RBCs in the model mice were reduced. The glutathione (GSH) levels in blood plasma were decreased. The liver, spleen, kidney had no detectable changes.

Conclusion: To the best of our knowledge, these effects represent the success of a novel anemia model by compelled acute exercise. The oxidative damages on RBC and hemorheological changes are in part the causes of acute anemia in this model.
\end{abstract}

Keywords: anemia; mice; hemorheology; hematocrit; hemoproteins

Acta Pharmacologica Sinica (2009) 30: 1643-1647; doi: 10.1038/aps.2009.161

\section{Introduction}

Novel anemia models are important for pharmacology, physiology, preclinical medicine, athletic medicine and preventive medicine research ${ }^{[1]}$.

Anemia is a condition in which blood has a lower number of red blood cells than normal. This condition also can occur if red blood cells don't contain enough hemoglobin ${ }^{[2]}$. According to the Anemia Standards by the National Institutes of Health $(\mathrm{NIH})$, we know there are 3 standards of anemia in adult males: red blood cell(RBC) number $<4.0 \times 10^{12} / \mathrm{L}$ or hemoglobin concentration $<120 \mathrm{~g} / \mathrm{L}$ or hematocrit $<0.4$.

Although there are many anemia models, such as hypoferric anemia, blood loss anemia, hemolytic anemia, they are still not effective enough for physiology and athletic medicine research. There is still a shortage of suitable acute anemia model induced by compelled exercise $\mathrm{e}^{[3,4]}$.

The first aim of the study is to develop an acute anemia model in mice using compelled exercise. The second aim is

\footnotetext{
\# These authors contribute equally to this work.

* To whom correspondence should be addressed.

E-mail dugh@imm.ac.cn

Received 2009-03-14 Accepted 2009-09-29
}

to investigate the mechanisms mediated in this novel anemia model.

To research the mechanisms of the model lead by acute compelled exercise, we investigated the number of RBC, hemorheological changes, anti-oxidative ability ${ }^{[5,6]}$ and observed pathological changes in liver, spleen and kidney for these organ associated with bleeding or congestion.

\section{Materials and methods \\ Reagent}

Supporting reagents for a hematology analyzer were purchased from BECKMAN COULTER corporate. Assay kits for analyzing malondialdehyde (MDA) and GSH were purchased from Nanjing Jiancheng Corporate (China). If not mentioned otherwise in text, any other chemicals were of molecular grade and purchased/obtained from Chinese Beijing Xinjingke Corporate.

\section{Animals}

The experiments were carried out in compliance with the guidelines for animal care and use of China and the experimental protocols were approved by the animal ethics committee of the Chinese Academy of Medical Sciences and Peking 
Union Medical College. Twenty-four Kunming mice (20 \pm 2 g, aged 3 weeks, male or female randomly) were single-housed in a light (12 h on and $12 \mathrm{~h}$ off $)$, temperature $\left(23 \pm 2{ }^{\circ} \mathrm{C}\right)$ and humidity $(40 \%-60 \%)$ controlled specific-pathogen free environment, with standard mice chow and water available ad libitum. The mice were obtained from and the diet was prepared by the Institute of Laboratory Animal, Chinese Academy of Medical Sciences and Peking Union Medical College.

Mice were acclimated to single-housing and daily human handling to reduce stress for at least one week prior to experimental procedures ${ }^{[7,8]}$. Instruments were made by Institute of Material Medica, Chinese Academy of Medical Science that can generate $1 \mathrm{mV}$ electricity. This instrument was used to generate an animal model of depression by low voltage electricity $^{[6]}$. The mice were divided equally into two groups: an anemia group in which mice were placed into the instrument to jump and run for $30 \mathrm{~min}$, and the control group in which mice be placed into the instrument without electric stimulation. Mice also stay in it for $30 \mathrm{~min}$. The low voltage is safe for mice, but it can make mice feel irritable and unhappy.

\section{Measurement of RBC count, hemoglobin and hematocrit}

Immediately after exercise, the mouse tails mice were cut and $20 \mu \mathrm{L}$ whole blood was obtained and used to detect the RBC count, hemoglobin and hematocrit with a Hematology analyzer (MEK-6318, made in Japan).

\section{Measurement of cell osmotic fragility}

Solutions with different osmotic concentrations (0 to 300 $\mathrm{mOsm} / \mathrm{kg}$ ) were prepared by mixing D-PBS with distilled water in various proportions. Ten aliquots of $1000 \mu \mathrm{L}$ cell suspensions $\left(2 \times 10^{6}\right.$ cells $\left./ \mathrm{mL}\right)$ were placed in 10 centrifuge tubes. The supernatant was removed after centrifugation at $600 \times g$ for $5 \mathrm{~min}$. $500 \mu \mathrm{L}$ of solutions with different osmotic concentrations were added to these tubes and mixed. 30 min later, the numbers of non-hemolyzed cells in different tubes were counted with a blood cell counting chamber, and the number was divided by that in the control tube $(300 \mathrm{mOsm} / \mathrm{kg})$ to obtain the percentages of non-hemolyzed cells ${ }^{[9]}$.

\section{Measurement of deformation index, orientation index and small deformation index}

The deformation index, DI, of the samples was measured by an ektacytometer (Model LBY-BX2 made in China) at shear rate from $50-1000 \mathrm{~s}^{-1}{ }^{[9]}$. The value of DI at the maximum shear rate $1000 \mathrm{~s}^{-1}$ is designated as (DI) $\max$. Similarly, the RBC were suspended in a $1.25 \%$ PVP and adjusted to $2 \times 10^{7} /$ $\mathrm{mL}$ for the new ektacytometry. The value of $O I$ and $(D I) \mathrm{d}$ at the maximum shear rate $150 \mathrm{~s}^{-1}$ are designated as $O I_{\max }$ and $(D I)_{\mathrm{d} \cdot \max }{ }^{[10,11]}$.

\section{The measurement of MDA and GSH}

Blood serum or TBA was added into 96 well Costar plates, then, $30 \mu \mathrm{L}$ different concentrations of TEP were added into the same well and mixed. The plate was incubated for $40 \mathrm{~min}$ at $60{ }^{\circ} \mathrm{C}$. The optical density $(O D)$ was obtained at $532 \mathrm{~nm}$ with M5 (MDs, USA). The standard curve was made according to OD value ${ }^{[12]}$.

$30 \mu \mathrm{L}$ blood serum of model mice was added into 96-well Costar plates. $170 \mu \mathrm{L}$ TBA was added into the same well and mixed fully. The plate was incubated for $40 \mathrm{~min}$ at $60{ }^{\circ} \mathrm{C}$. After incubation, the optical density $(O D)$ was obtained at 532 $\mathrm{nm}$. The MDA concentration was determined according to the standard curve.

Blood was taken from control mice and model mice, and centrifuged for $15 \mathrm{~min}$ at $3000 \mathrm{r} / \mathrm{min}$ to obtain serum was obtained. According to protocol of GSH Assay kit, $20 \mu \mathrm{L}$ blood serum was added into 96-well Costar plates. $20 \mu \mathrm{L}$ WST working solution was added into the same well and mixed fully. $20 \mu \mathrm{L}$ enzyme working solution was added into same wells, and incubated for $20 \mathrm{~min}$ at $37^{\circ} \mathrm{C}$. After incubation, the plate was measured at $450 \mathrm{~nm}$ with a screening machine (M5, MDs corparate, USA). GSH concentration was determined according to the given standard curve.

\section{Methods of pathology research}

Immediately after exercise, all mice were sacrificed by decapitation and the liver, spleen and kidney were surgically removed for pathologic examination using HE staining.

\section{Statistical analysis}

Values are mean \pm SD. Statistical differences were calculated with an analysis of variance and $P<0.05$ was considered significant. ANOVA was used for statistic analysis.

\section{Results}

The change of RBC count, hemoglobin, hematocrit in model mice

In the model group, all mice were found to be anemia, and the count of RBC, hemoglobin and hematocrit of model mice were decreased. The RBC count, hemoglobin, hematocrit in model mice are decreased by $42 \%, 26 \%$, and $19 \%$, respectively, compared with that in control mice. We carried out routine examination of blood in control mice and model mice. We found that mice in the model group are anemic, and that the count of $\mathrm{RBC}$, hemoglobin concentration and hematocrit of model mice were lower than that of control mice $(P<0.05)$. The results were shown in Table 1.

The difference of osmotic fragility between model mice and control mice

In the model group, the number of broken RBC was much more than that of control group. The RBC in the model group

Table 1. The count of RBC, hemoglobin and hematocrit of mice. Each data represents the mean \pm SD. $n=12$. ${ }^{\mathrm{b}} P<0.05$ vs control group.

\begin{tabular}{lcc}
\hline \multicolumn{1}{c}{ Group } & Control group & Model group \\
\hline RBC count $\left(\times 10^{12} / \mathrm{L}\right)$ & $6.03 \pm 0.38$ & $3.49 \pm 0.32^{\mathrm{b}}$ \\
Hemoglobin concentration $(\mathrm{g} / \mathrm{L})$ & $150.31 \pm 33.13$ & $110.49 \pm 29.32^{\mathrm{b}}$ \\
Hematocrit $(\%)$ & $42.21 \pm 2.37$ & $34.25 \pm 2.84^{\mathrm{b}}$ \\
\hline
\end{tabular}


had an increased osmotic fragility compared to control mice, and this may lead to more destroyed RBCs in mice, This may be one reason for anemia of in the model mice (Figure 1).

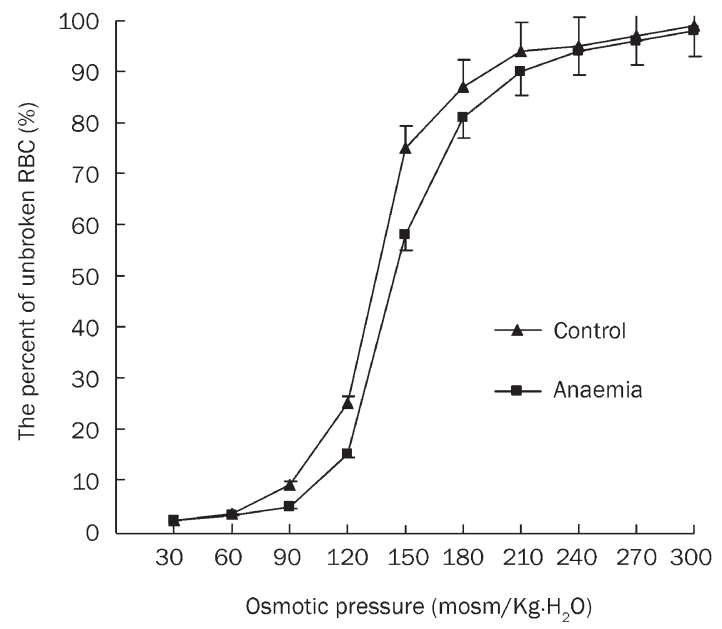

Figure 1. Curve of osmotic fragility of RBC in control mice and model mice. Each column represents the mean \pm SD. $n=12$.

Deformation index, orientation index and small deformation index

The deformation index (DI) and orientation index (OI) of RBCs in model mice decreased more than that of control mice $(P<0.05)$. The results were shown in Figure 2.

\section{The changes of plasma MDA and GSH in blood serum}

In the model group, the plasma MDA increased and GSH decreased significantly more than that of control mice $(P<0.05)$. The results were shown in Figure 3.

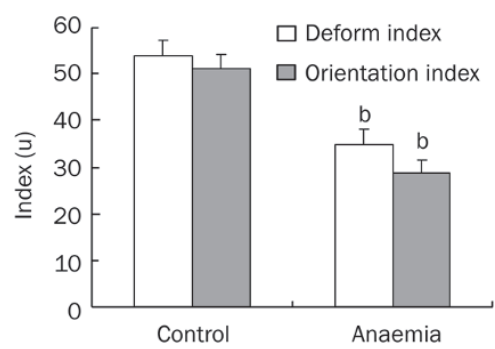

Figure 2. The effects of acute exercise on deformation index (DI) and orientation index OI of RBC. Each column represents the mean $\pm S D$. $n=12 .{ }^{\mathrm{b}} P<0.05$ vs control group.

\section{The pathology of liver, spleen, and kidney of mice}

In the model group, the cell morphology of liver, spleen and kidney are still the same as control mice. The cell nucleus and cytoplasm have no abnormal changes compared with the control group. The results were shown in Figure 4-6.

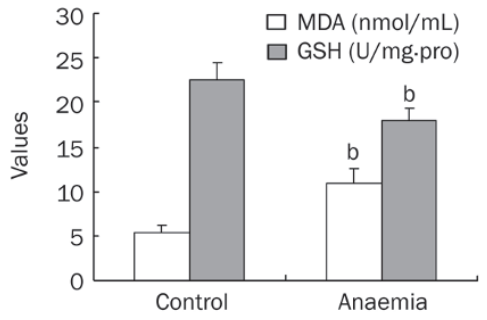

Figure 3. The effects of acute exercise on plasma MDA and GSH. Each column represents the mean \pm SD. $n=12$. ${ }^{\mathrm{b}} P<0.05$ vs control group.
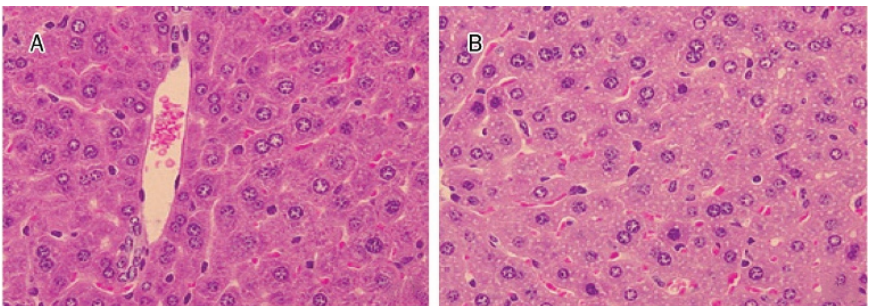

Figure 4. HE staining of liver. (A) The liver of control mice $(\times 400)$. (B) The liver of model mice $(\times 400)$.
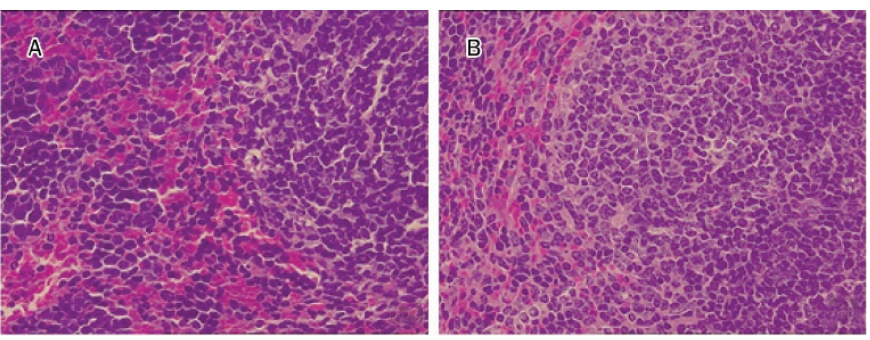

Figure 5. HE staining of spleen. (A) Spleen of control mice $(\times 40)$. (B) Spleen of model mice $(\times 400)$.
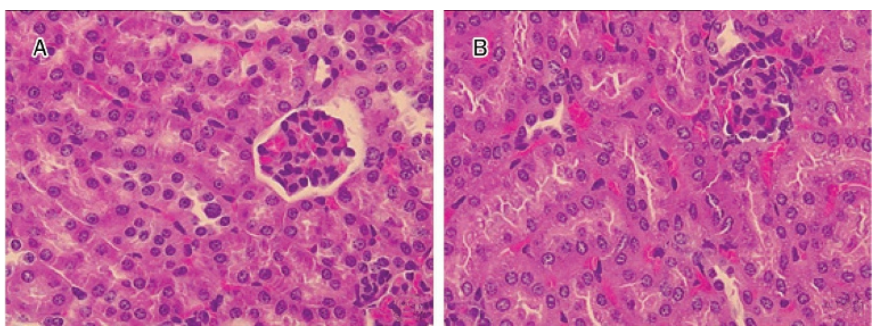

Figure 6. HE staining of kidney. (A) Kidney of control mice $(\times 400)$. (B) Kidney of model mice $(\times 400)$.

\section{Discussion and conclusions}

Anemia models can be used in pharmacology, physiology, preclinical medicine, athletic medicine and preventive medicine research. There is still a shortage of suitable acute anemia models induced by compelled exercise, so it is important to develop a novel anemia model ${ }^{[3]}$.

From Table 1, the count of RBC, hemoglobin and hematocrit 
of mice are all decreased significantly and immediately after compelled acute exercise. The result is interesting, but the mechanism requires further exploration.

Anemia is a condition in which blood has a lower number of RBCs or contains low hemoglobin concenations in RBCs. Usually anemia is caused by three main reasons: blood loss, lack of red blood cell production, or high rates of red blood cell destruction. The RBC production rate could be reason for anemia in this study, but blood loss and RBC destruction are the more likely possible causes of the anemia mode ${ }^{[3]}$.

By pathologic examination, we found that exercise in mice doesn't lead to loss of blood obviously in spleen, liver, kidney and intestine. We hypothesize that RBC destruction partly contributes to murine anemia. In results of Gillen's study, the plasma volume decreased by $15 \%$ first in prolonged exercise, then later plasma volume recovered or "expanded" ${ }^{[13]}$. In some study, post exercise volume expansion occurred 1-2 day after high activity exercise $(>90 \mathrm{~min})^{[14]}$. Plasma volume decreased immediately in acute compelled exercise. The RBC production rate is not important to anemia in mice exercised for 30 minutes.

According to our results, cholerythrin of exercised mice increased more than that of control mice. We think that RBC destruction is one important reason leading to anemia ${ }^{[15,16]}$. The cause of RBC destruction is discussed below.

Oxidative damage caused by free radical and lipid peroxidation increased in acute compelled exercise. This is one reason for destruction of RBCs and anemia ${ }^{[17,18]}$. Our results further confirmed the previous results which proved free radical are produced in acute exercise $\mathrm{e}^{[19,20]}$.

In our experiment, we found that the concentration of MDA in blood plasma increased. the deformability of RBC decreased and shape of RBC got worse. These results elucidated part of the mechanisms of the anemia model ${ }^{[21]}$.

According to our results, MDA increased in the serum plasma of model mice. SOD and GSH in serum plasma of model mice were decreased significantly than exercised mice. MDA is a final product of membrane lipid peroxidation, which can be used to evaluate oxidation in serum or cell membranes $^{[22]}$. SOD is an important antioxidant enzyme to clear oxygen-derived free radicals. We hypothesized that during acute compelled exercises, much free radical was produced, and more SOD and GSH were expended by increased free radicals $^{[12]}$. The deformability of cell membrane was destroyed, and the RBC were easily destroyed in the microcirculation or the spleen.

In summary, RBC count, hemoglobin concentration and hematocrit of model mice are in accordance with anemia standards. The anemia model is easily generated, convenient and cheap for pharmacology research. All in all, part of the mechanism of this anemia model is detailed below. Firstly, acute compelled exercise leads to increased oxidative stress, and SOD and GSH are destroyed by the oxidative stress. Secondly, lipid peroxidation leads to enhanced MDA. Thirdly, the osmotic fragility and cell deformability decreased, and the latter leads to RBC broken and anemia.

\section{Acknowledgements}

Experimental works conducted in the authors' laboratories were supported by Chinese High Technological Project (№ 2004AA2Z3782) and National Natural Science Foundation (№ 0630073, 30973959).

\section{Author Contribution}

Professor Guan-hua DU designed research; Jin-hua WANG and Qing-shan LIU performed research; Qing-shan LIU, Jinhua WANG and jian CUI analyzed data; Qing-shan LIU, Jinhua WANG and Zhi-hong YANG wrote the paper.

\section{References}

1 Sauter KA, Melton-Celsa AR, Larkin K, Troxell ML, O'Brien AD, Magun $B E$. Mouse model of hemolytic-uremic syndrome caused by endotoxinfree Shiga toxin 2 (Stx2) and protection from lethal outcome by antiStx2 antibody. Infect Immun 2008; 76: 4469-78.

2 Brion MJ, Leary SD, Smith GD, McArdle HJ, Ness AR. Maternal anemia, iron intake in pregnancy, and offspring blood pressure in the Avon Longitudinal Study of Parents and Children. Am J Clin Nutr 2008; 88: 1126-33.

3 Clark SF. Iron deficiency anemia. Nutr Clin Pract 2008; 23: 128-41.

4 Beard BC, Kiem HP. Canine models of gene-modified hematopoiesis. Methods Mol Biol 2009; 506: 341-61.

5 Connes P, Hue O, Tripette J, Hardy-Dessources MD. Blood rheology abnormalities and vascular cell adhesion mechanisms in sickle cell trait carriers during exercise. Clin Hemorheol Microcirc 2008; 39: 179-84.

6 Frazer A, Morilak DA. What should animal models of depression model? Neurosci Biobehav Rev 2005; 29: 515-23.

7 Liu QS, Wang QJ, Du GH, Zhu SY, Gao M, Zhang L, Zhu JM, Cao JF. Recombinant human ciliary neurotrophic factor reduces weight partly by regulating nuclear respiratory factor 1 and mitochondrial transcription factor A. Eur J Pharmaco 2007; 563: 77-82.

8 Liu QS, Gao M, Zhu SY, et al. The novel mechanism of recombinant human ciliary neurotrophic factor on the anti-diabetes activity. Basic Clin Pharmacol Toxicol 2007; 8: 78-84.

9 Yao W, Gu L, Sun D, Ka W, Wen Z, Chien S. Wild type p53 gene causes reorganization of cytoskeleton and, therefore, the impaired deformability and difficult migration of murine erythroleukemia cells. Cell Motility Cytoskeleton 2003; 56: 1-12.

10 Sun D, Wang J, Yao W, Gu L, Wen Z, Shu C. Tumorigenesis of murine erythroleukemia cell line transfected with exogenous p53 gene. Clin Hemorheol Microcirc 2004; 30: 117-26.

11 Wang J, Ka W, Tang Z, Sun D, Wen Z. Reheological studies on precursor cells at different stage in mice. Clin Hemorheol Microcirc 2003; 29: 63-9.

12 Ficicilar H, Zergeroglu AM, Tekin D, Ersoz G. The effects of acute exercise on plasma antioxidant status and platelet response. Thromb Res 2003; 111: 267-71.

13 Buchheit M, Laursen PB, Al Haddad H, Ahmaidi S. Exercise-induced plasma volume expansion and post-exercise parasympathetic reactivation. Eur J Appl Physiol 2009; 105: 471-81.

14 Kay B, O’Brien BJ, Gill ND. Plasma volume expansion 24-hours postexercise: effect of doubling the volume of replacement fluid. J Sports Sci Med 2005; 4: 179-84.

15 Brzeszczynska J, Pieniazek A, Gwozdzinski L, Gwozdzinski K, Jegier A.Structural alterations of erythrocyte membrane components induced by exhaustive exercise. Appl Physiol Nutr Metab 2008; 33: 1223-31. 
16 Shimotakahara A, Kuebler JF, Vieten G, Kos M, Metzelder ML, Ure BM. Carbon dioxide directly suppresses spontaneous migration, chemotaxis, and free radical production of human neutrophils. Surg Endosc 2008; 22: 1813-7.

17 Marriott HM, Jackson LE, Wilkinson TS, Simpson AJ, Mitchell TJ, Buttle $D J$, et al. Reactive oxygen species regulate neutrophil recruitment and survival in pneumococcal pneumonia. Am J Respir Crit Care Med 2008; 177: 887-95.

18 Nakaji S, Umeda T, Matsuzaka M, Takahashi I, Tanabe M, Danjo K, et al. Effects of long-term training on neutrophil function in male university judoists. Br J Sports Med 2008; 42: 255-9.

19 Hashimoto T, Brooks GA. Mitochondrial lactate oxidation complex and an adaptive role for lactate production. Med Sci Sports Exerc 2008; 40: 486-94.

20 Yaegaki M, Umeda T, Takahashi I, Yamamoto Y, Kojima A, Tanabe $\mathrm{M}$, et al. Measuring neutrophil functions might be a good predictive marker of overtraining in athletes. Luminescence 2008; 23: 281-6.

21 Larcombe SD, Tregaskes CA, Coffey JS, Stevenson AE, Alexander L, Arnold KE. The effects of short-term antioxidant supplementation on oxidative stress and flight performance in adult budgerigars Melopsittacus undulatus. J Exp Biol 2008; 211: 2859-64.

22 Morgan MJ, Kim YS, Liu ZG. TNFalpha and reactive oxygen species in necrotic cell death. Cell Res 2008; 18: 343-9.

\section{The 4th International Conference on Bioinformatics and Biomedical Engineering (iCBBE 2010)}

June 18-20, 2010, Chengdu, China

For detailed information, please login

http://www.icbbe.org/2010 